\title{
Effect of long-term food restriction on pituitary sensitivity to cLHRH-I in broiler breeder females
}

\author{
V. Bruggeman ${ }^{1}$, O. Onagbesan ${ }^{1}$, D. Vanmontfort ${ }^{1}$, L. Berghman ${ }^{2}$, \\ G. Verhoeven ${ }^{3}$ and E. Decuypere ${ }^{1}$

\begin{abstract}
${ }^{1}$ Laboratory for Physiology and Immunology of Domestic Animals, Catholic University of Leuven, Kardinaal Mercierlaan 92, 3001 Heverlee, Belgium; ${ }^{2}$ Laboratory for Neuroendocrinology and Immunological Biotechnology, Zoological Institute, Catholic University of Leuven, Naamsestraat 59, 3000 Leuven, Belgium; and ${ }^{3}$ Laboratory for Experimental Medicine and Endocrinology, Onderwijs and Navorsing, Catholic University of Leuven, Gasthuisberg, 3000 Leuven, Belgium
\end{abstract}

The effect of long-term food restriction on the sensitivity of the pituitary to exogenously administered chicken luteinizing hormone releasing hormone I (cLHRH-I) was investigated in three groups of broiler breeder females fed ad libitum, fed a restricted quantity of food or fed a restricted quantity of food to obtain an intermediate body weight between those of the first two groups. At 16 weeks of age, basal FSH release was higher in ad libitum fed birds, culminating in ovarian development and subsequent oestradiol production by the small follicles. At this age, LH secretion was independent of ovarian feedback factors. In all groups, cLHRH-I was most active in releasing LH in intact and ovariectomized animals and, to a lesser extent, in releasing FSH in ovariectomized birds. At 39 weeks of age, basal FSH concentrations were similar among intact animals of all groups, whereas LH concentrations differed among groups, with higher values in the restricted birds. This food effect was enhanced in ovariectomized birds. Furthermore, the high response to CLHRH-I in the ovariectomized, restricted birds compared with the ad libitum, ovariectomized group suggests an improved sensitivity of the hypothalamic-pituitary axis. In conclusion, birds fed ad libitum showed the highest responsiveness to ovarian factors and to CLHRH-I in releasing FSH in the period before sexual maturity. No effect of amount of feeding could be observed for LH. However, during the egg laying period, LH release by cLHRH-I was highly dependent on amount of feeding and on ovarian feedback regulation. This finding indicates that the amount of feeding can modify the sensitivity of the pituitary to cLHRH-I, and possibly to gonadal hormones, during the laying period.

\section{Introduction}

In domestic poultry, there is a strong negative relationship between body weight and reproductive efficiency. Concomitant with improvements in the growth rate of broiler chickens, the ability of meat-type parent stocks to reproduce has been severely reduced. Nevertheless, parents of meat-type poultry should not only have the genetic potential to exhibit fast and efficient growth but must also be capable of reproducing. Broiler breeders fed ad libitum develop an excess of large yellow follicles. The increased incidence of erratic ovipositions (ovipositions outside the normal period of laying when compared with egg-type chickens) and defective eggs is the result of the simultaneous development of follicles combined with excessive ovulations (Jaap and Muir, 1968; Hocking et al., 1987, 1989). Empirically, it is known that broiler breeders require dedicated pro-

*Correspondence.

Revised manuscript received 11 June 1998. grammes of food restriction that delay the onset of egg production but improve reproductive performance (Costa, 1981; Yu et al., 1992; Hocking, 1993). In practice, the application of the restriction programme implicates the importance of carry-over effects of a specific amount of feeding (especially during rearing) on the development and functioning of the reproductive axis. LH and FSH are of major importance in ovarian development, follicular recruitment and ovulation of follicles in poultry. Both $\mathrm{LH}$ and FSH synthesis and secretion are controlled by a complex interaction between the stimulatory action of hypothalamic gonadotrophin releasing hormone $(\mathrm{GnRH})$ and the negative and positive feedbacks of gonadal substances (steroids and inhibin).

In mammals, literature on the effect of chronic food restriction on the responsiveness of the pituitary to $\mathrm{GnRH}$ is scarce. Roberson et al. (1992) indicated that body condition of heifers fed diets of low energy content modulates the pattern of $\mathrm{LH}$ in the circulation, the responsiveness of the pituitary to $\mathrm{GnRH}$ and releasable stores of $\mathrm{LH}$. In rats, reproductive 
senescence is delayed by a moderate life-long caloric restriction (McShane and Wise, 1996). The beneficial effects of restricted feeding on extended reproductive life span may be acting via central effects on the $\mathrm{GnRH}$ pulse generator and other neuroendocrine systems, influencing the reproductive neuroendocrine axis at the hypothalamus or pituitary responsiveness to GnRH (McShane and Wise, 1996).

Data from previous studies showed that the long-term restricted feeding of broiler breeder females influenced: (1) luteinizing hormone releasing hormone I (LHRH-I) concentrations in the median eminence; (2) pituitary content of $\mathrm{LH}$ and $\mathrm{FSH}$ in the period before the onset of lay (Bruggeman et al., 1998); and (3) plasma LH and FSH concentrations during the rearing and laying period (Bruggeman, 1998). These results indicate that the synthesis and secretion of the gonadotrophins in the period before the onset of lay (and possibly during laying) could depend on nutritional stimuli, acting via differences in LHRH-I content or release, or in the sensitivity of the pituitary to LHRH-I.

The present study investigates how chronic food restriction influences the sensitivity of the pituitary by measuring the gonadotrophin response after exogenous administration of CLHRH-Y in control and ovariectomized animals at two different ages: before sexual maturity and during egg laying. Birds were ovariectomized to exclude possible feedback effects from ovarian substances. Thus, effects of the previous food intake could be completely separated from ovarian effects on the pituitary. Basal concentrations of oestradiol, progesterone and inhibin are included to explain the possible changes in $\mathrm{LH}$ and FSH concentrations in the differently fed groups before and after ovariectomy.

\section{Materials and Methods}

\section{Animals and managment}

Three hundred 1-day-old female Hybro G broiler breeder chicks (Euribrid, Boxmeer) were raised on floor pens. Chicks were fed chick starter diet (11.7 $\mathrm{MJ} \mathrm{kg}^{-1}$ metabolizable energy, $18.5 \%$ crude protein (CP)) ad libitum for the first week. From 2 weeks onwards, they were assigned to three feeding groups according to the experimental design. From 4 weeks of age onwards, the food was changed to chick grower pellet (11.3 MJ $\mathrm{kg}^{-1}$ metabolizable energy, 15\% CP) and, 3 weeks before the expected time of laying, chicks were fed on pre-lay food (11.5 MJ kg-1 metabolizable energy, 17\% CP) up to point of lay, depending on the experimental feeding regimen. Access to water was unrestricted. Birds were maintained on a lighting schedule as recommended by the breeder company. The birds were reared under $23 \mathrm{~h}$ light: $1 \mathrm{~h}$ dark for the first 2 weeks, decreased by $3-4 \mathrm{~h}^{\text {week }}{ }^{-1}$ to $8 \mathrm{~h}$ light: $16 \mathrm{~h}$ dark at week 6 . Birds were photostimulated from 19 weeks of age onwards by increasing the weekly photoperiod by $2 \mathrm{~h}$ to reach $14 \mathrm{~h}$ light: $10 \mathrm{~h}$ dark at 21 weeks of age. At week 16, birds were kept under $8 \mathrm{~h}$ light: $16 \mathrm{~h}$ dark, whereas the lighting schedule during the laying period was $14 \mathrm{~h}$ light: $10 \mathrm{~h}$ dark.

\section{Experimental design}

After 1 week of ad libitum food, chicks were divided into three groups (100 birds per group). One group was fed ad libitum (Ad lib), a second was fed on a restricted quantity of food (Res), as recommended by the breeder company, and a third group was restricted to obtain an intermediate body weight (Int) between the Ad lib and the Res groups. The body weights of the animals in the three groups were recorded each week by weighing 15 animals randomly per group so that the amount of food for obtaining the desired body weight curve could be adjusted. The body weight curves and daily food intakes are similar to those described in Bruggeman et al. (1997). Average body weights at week 16 were $1376 \pm 60 \mathrm{~g}, 2595 \pm 66 \mathrm{~g}$ and $3685 \pm 75 \mathrm{~g}$ for the Res, Int and Ad lib groups, respectively. At week 39 , body weights were $3952 \pm 72 \mathrm{~g}, 4516 \pm 123 \mathrm{~g}$ and $4815 \pm 143 \mathrm{~g}$ for the same groups, respectively.

Ovariectomy was performed at two different ages, before sexual maturation (week 16) and during the egg laying period (week 38). Ovariectomy was conducted under sodium pentobarbital (Nembutal; $400 \mu \mathrm{l} \mathrm{kg}^{-1}$ i.v.; Abbott Laboratories, Brussels) anaesthesia. At 16 weeks of age, the ovary was removed by cauterization. During the laying period, ovariectomy of intact hens was impossible because of the high vascularization of the ovary. Surgery at this age was performed after a period of severe food restriction of 21 days to avoid extensive bleeding (ADAS method: 1 day of food withdrawal followed by 20 days of restricted wheat bran; Wakeling, 1985) by inducing regression of the ovary. Only small white follicles were left after this period of food restriction. The remaining ovary was removed by cauterization. The completeness of the ovariectomy was checked at the end of the experiment. A food restricted shamoperated group was included besides the intact group during the laying period to exclude possible effects of the short-term food restriction. The birds were allowed to recover for 1 week after surgery and had ad libitum access to food after the surgical procedure, which was preceded by a period of food restriction ( 3 weeks). This ad libitum feeding was done to investigate the sole effects of the feeding regimen before this restriction period and surgery. Intact animals were fed on their previous feeding regimen (Ad lib, Int, Res) during this week, although food intake did not differ much among the Ad lib, Int and Res birds from the start of lay until this age (about $150-200 \mathrm{~g} \mathrm{day}^{-1}$ per animal). All birds were injected at the age of 39 weeks. Injections were given in all experimental groups in the same week.

At both ages, six intact, six ovariectomized and six shamoperated (only present at 39 weeks of age) hens per group were injected i.v. with cLHRH-I (Sigma Chemie, Bornem) at a

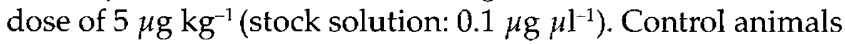
$(n=6)$ of each experimental group (week 16: intact and ovariectomized; week 39: intact, food restricted plus ovariectomized and food restricted plus sham-operated) per food group (Ad lib, Int, Res) were injected with $0.9 \%(\mathrm{w} / \mathrm{v})$ $\mathrm{NaCl}$. Blood samples $(2-3 \mathrm{ml})$ were taken from the brachial vein immediately before injection and, subsequently, at 2, 5, 10 and $30 \mathrm{~min}$ after injection. The blood samples just before injections were used to study the effects of short-term food 
restriction and ovariectomy on the basal concentrations of different hormones. Blood was collected into heparinized tubes. Plasma was separated by centrifugation at $4000 \mathrm{~g}$ for $15 \mathrm{~min}$ and stored at $-20^{\circ} \mathrm{C}$ until analysis for $\mathrm{FSH}, \mathrm{LH}$, oestradiol, progesterone (only at week 39 ) and inhibin by radioimmunoassay. All samples were run in the same assay.

\section{Radioimmunoassays}

Radioimmunoassay of FSH. FSH was measured using a homologous radioimmunoassay (Krishnan et al., 1993). The chicken FSH (cFSH) radioimmunoassay kit, kindly provided by J. A. Proudman (USDA; ARS, Beltsville, MD), includes a highly purified preparation of cFSH (USDA-cFSH-K-1; Krishnan et al., 1992), used as immunogen and standard, and a polyclonal rabbit antiserum (USDA-AcFSH-16). Chicken FSH (USDA-cFSH-I-1) was labelled using a stoichiometric chloramine- $\mathrm{T}$ procedure according to the method of Proudman and Opel (1981). Briefly, the iodination mixture was purified by gel filtration on a PD-10 column (Pharmacia, Uppsala). The resulting tracer was further purified on a Sephadex G-75 column $(1.6 \times 85 \mathrm{~cm})$ and the fractions with the highest specific binding to the USDA-cFSH antibody were pooled for use in the assay. The antiserum showed no crossreaction with different purified preparations of chicken LH, turkey LH, purified chicken growth hormone $(\mathrm{GH})$, recombinant chicken $\mathrm{GH}$, turkey $\mathrm{GH}$ or turkey prolactin. The recovery of added cFSH was $100.5 \pm 5.1 \%$ (mean \pm SEM). The detection concentration of the assay was $0.6 \mathrm{ng} \mathrm{ml}^{-1}$. The intra-assay coefficient of variation was $4.8 \%$.

Radioimmunoassay of $L H$. An homologous radioimmunoassay of cLH (Krishnan et al., 1994) was used with reagents, supplied by J.A. Proudman and D. J. Bolt (USDA; ARS, Beltsville). The assay was performed according to the recommendations supplied with the radioimmunoassay reagents. Chicken LH (USDA-cLH-I-1) was radioiodinated in the same way as for cFSH. The iodination mixture was purified by gel filtration on a PD-10 column (Pharmacia, Uppsala). The radioimmunoassay was performed using USDA-cLH-K-3 as standard. Crossreactivity was $<3 \%$ with $\mathrm{cFSH}$, and $<0.9 \%$ with turkey prolactin, $\mathrm{cGH}$ and recombinant cGH. Separation of bound and free radioactivity was obtained by addition of $100 \mu 1$ of second antibody-coated cellulose suspension (Innogenetics, Gent) per tube, addition of $1 \mathrm{ml}$ distilled water after a $30 \mathrm{~min}$ incubation, centrifugation at $4500 \mathrm{~g}$ for $15 \mathrm{~min}$ and removal of the supernatant by aspiration. The lowest detectable concentration of $\mathrm{LH}$ was $0.1 \mathrm{ng} \mathrm{ml}^{-1}$. The intra-assay coefficient of variation was $3.3 \%$.

Radioimmunoassay of steroid hormones. Plasma progesterone was measured by radioimmunoassay as described by Verheyen et al. (1987) and oestradiol concentrations were measured by radioimmunoassay using the technique developed by Cailleau (1979) and adapted for hens as described by Verheyen et al. (1987). The standards ranged from 12.5 to $1000 \mathrm{pg} \mathrm{ml}^{-1}$ for oestradiol and from 20 to 2000

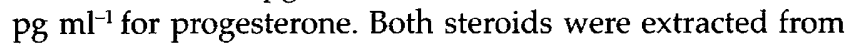
plasma with cyclohexane: ethylacetate $(1: 1, v / v)$. The oestradiol antiserum had a crossreactivity of $3.33 \%$ with oestrone, $0.31 \%$ with oestriol and $0.01 \%$ with androgens. The progesterone antibody was raised in rabbits against progesterone-3-CMO-BSA (UCB Bioproducts) with a crossreactivity of $1.5 \%$ for 17-hydroxyprogesterone and $\leq 0.3 \%$ for other progestagens, androgens and oestrogens, as reported by Cailleau (1979). Intra-assay variabilities were $4.01 \%$ for progesterone and $17.9 \%$ for oestradiol.

Radioimmunoassay of inhibin. Inhibin immunoreactivity was measured using a radioimmunoassay kit, kindly provided by D. M. de Kretser and D. M. Robertson, Monash University, Melbourne. The kit included a rabbit antiserum (number 1989) raised against highly purified bovine $31 \mathrm{kDa}$ inhibin and iodinated bovine $31 \mathrm{kDa}$ inhibin as a tracer. The antibody shows no crossreaction with bovine Müllerian inhibiting substance, bovine activin-A, free bovine $\beta$-subunits of inhibin, and human transforming growth factor- $\beta$ (Robertson et al., 1988). However, the $\alpha$-subunit of inhibin (Schneyer et al., 1990) and an $\alpha$-subunit precursor, pro- $\alpha C$, do crossreact in the assay (Robertson et al., 1989). Thus, inhibin immunoreactivity, as detected by number 1989 antiserum, represents concentrations of inhibin and $\alpha$-subunit products. This assay has been validated for the measurements of inhibin in chickens (Rombauts et al., 1992). The assay was performed essentially as suggested by Robertson et al. (1988), but a second antibody solid-phase system (SAC-cell; IDS Ltd., Boldon) was used to separate free and antibody-bound inhibin. A pool of plasma from a laying domestic hen (Gallus domesticus) was used as an in-house standard and was assigned an arbitrary value of $100 \mathrm{U} \mathrm{ml}^{-1}$. A chicken granulosa cell homogenate was used as the operational standard; $1 \mathrm{ml}$ of this standard corresponded to 66.7 units of the in-house standard or to 647.0 units of the international reference preparation, bINH-R-90/1, which was kindly provided by G. Bialy (NICHHD, Bethesda, MD). The detection concentration was $0.37 \mathrm{U} \mathrm{ml}^{-1}$. The intra-assay coefficient of variation was $3.18 \%$.

\section{Statistical analysis}

Values are expressed as means \pm SEM. All data were analysed by the general linear models procedure of SAS (1985). The statistical differences among data at the time before injection were assessed by Duncan's multiple range test. The statistical significances of the injection experiment were assessed by repeated measures analysis of variance.

\section{Results}

\section{FSH, LH, oestradiol and inhibin concentrations in intact and ovariectomized animals at 16 weeks of age}

In intact birds, FSH concentrations were significantly lower in the Res group compared with the Ad lib group $(P<0.05)$ (Fig. 1). After ovariectomy, basal FSH concentrations sharply increased (2.5-fold) in the Ad lib group $(P<0.05)$ and remained significantly higher than those of the Int and Res 

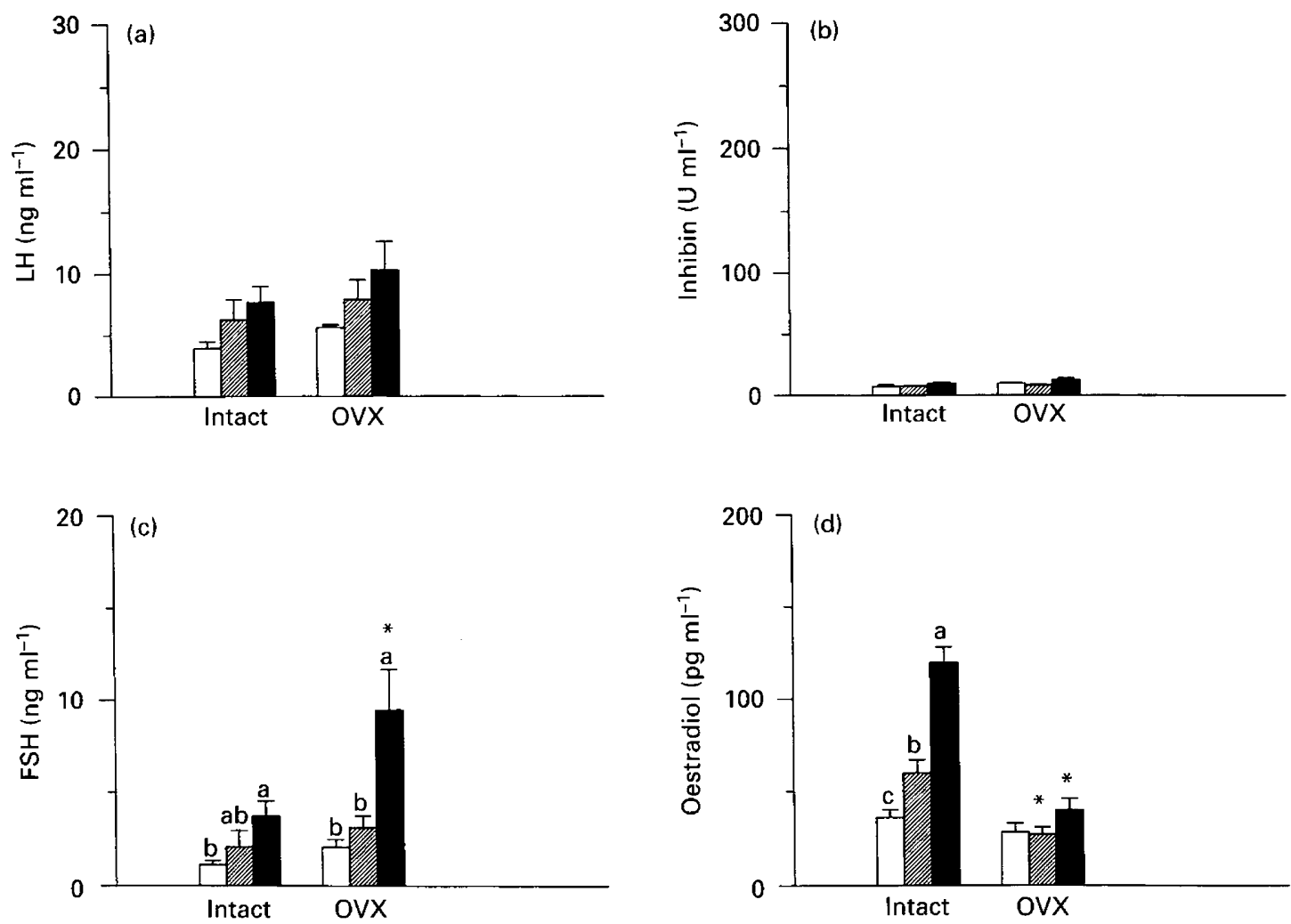

Fig. 1. Plasma concentrations of (a) LH, (b) inhibin, (c) FSH and (d) oestradiol in intact and ovariectomized (OVX) animals of restricted $(\square)$, intermediate $(\mathbb{Z})$ and ad libitum $(\square)$ fed broiler breeder females at week 16 . Significant differences $(P<0.05)$ between feeding groups of the same gonad groups are indicated by different letters. Asterisks indicate significant differences between gonad classes of the same feeding group $(P<0.05)$.

groups $(P<0.005)$. In the Res and Int groups, FSH tended to increase after ovariectomy, although not significantly.

No significant differences in LH and inhibin concentrations could be observed between the three different food groups of intact or ovariectomized animals.

Oestradiol concentration in the intact birds was highest in the Ad lib group, followed by the Int and Res birds $(P<0.0001)$. After ovariectomy, oestradiol concentrations decreased significantly $(P<0.005)$ in the $\mathrm{Ad} \mathrm{lib}$ and Int groups, while no effect could be observed in the Res birds.

\section{Effects of cLHRH-I injections into intact and} ovariectomized animals on $L H$ and FSH concentrations at 16 weeks of age

In intact animals, the $\mathrm{LH}$ concentration increased in all groups after cLHRH-I injection (Fig. 2). However, no significant differences could be observed at all times among groups after either saline or cLHRH-I injections. $\mathrm{LH}$ values remained significantly higher in all intact groups, even after $30 \mathrm{~min}$, compared with the saline treated animals $(P<0.05)$. The response to cLHRH-I of the ovariectomized Ad lib group was less pronounced than that obtained for the ovariectomized Res group at all times $(P<0.05)$. The trend of the response to cLHRH-I of the ovariectomized Ad lib and Int groups was similar to that of the Res group.
No changes in FSH concentrations after cLHRH-I administration could be observed in intact animals (Fig. 3). Ovariectomized animals not only showed increased basal FSH concentrations compared with intact birds, but also tended to respond to cLHRH-I, although this response was not significant in any group. At all times, FSH concentrations were higher in the Ad lib group compared with the Res and Int groups after either saline or cLHRH-I injections $(P<0.05)$.

\section{Effects of short-term food restriction and ovariectomy on FSH, LH, oestradiol, progesterone and inhibin concentrations at 39 weeks of age}

Basal FSH concentrations did not differ among intact Res, Int and Ad lib chickens (Fig. 4). Similarly, food restricted sham-operated chickens showed similar concentrations among Res, Int and Ad lib animals. Ovariectomy increased basal FSH concentrations significantly in all food groups compared with their intact and sham-operated counterparts $(P<0.005)$. FSH concentrations in the ovariectomized Res group were higher compared with the ovariectomized Ad lib and Int groups, although this difference was not significant.

In intact birds, basal LH concentrations were higher in the severely restricted group (Res) compared with the Int and Ad lib groups $(P<0.05)$. LH concentrations increased after ovariectomy to significantly higher values compared with 

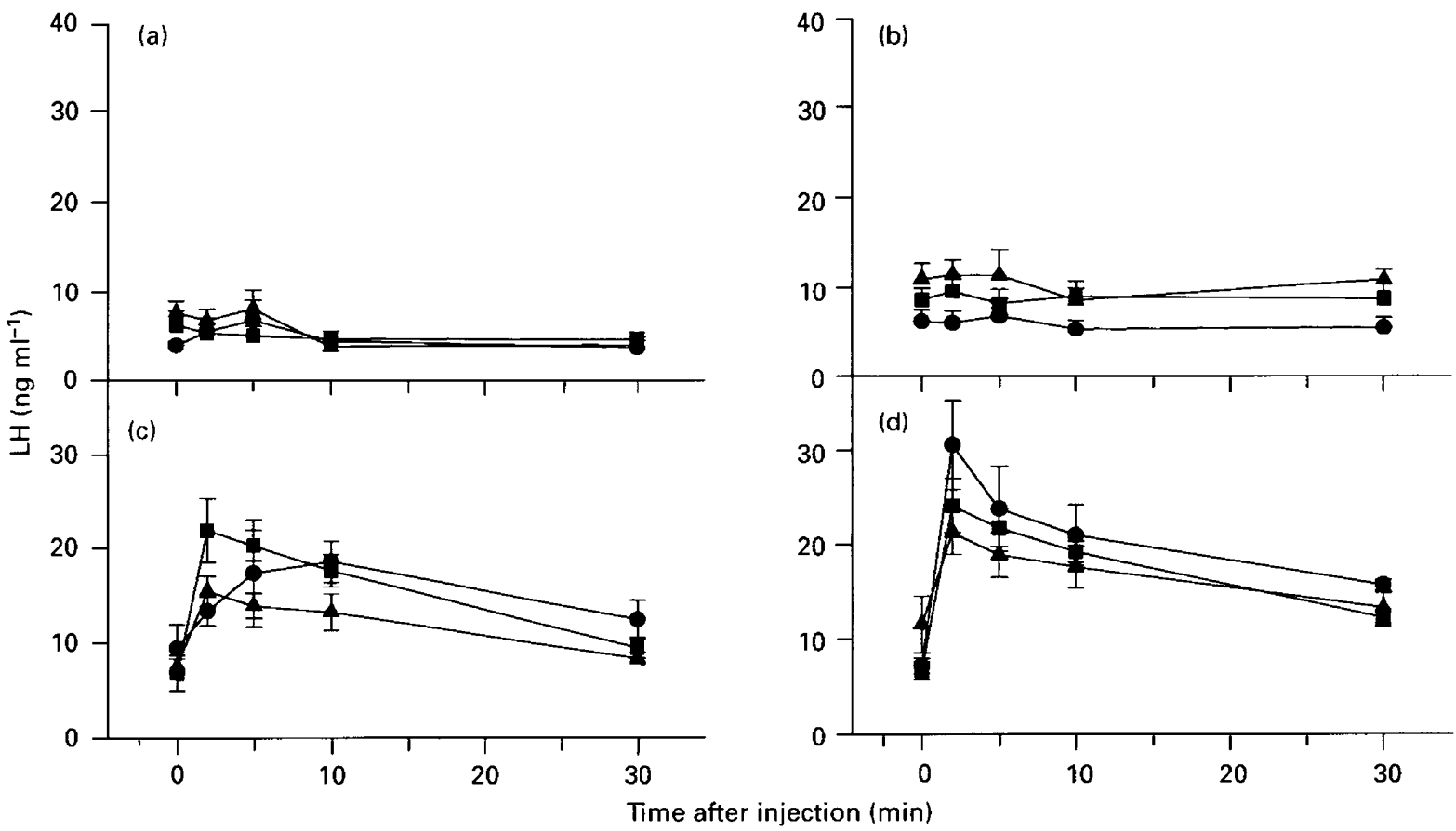

Fig. 2. Plasma LH concentrations in $(a, c)$ intact and $(b, d)$ ovariectomized animals of restricted $(\boldsymbol{O})$, intermediate $(\boldsymbol{\square})$ and $a d$ libitum (A) fed broiler breeder females after treatment with $(\mathrm{a}, \mathrm{b})$ saline $(0.9 \% \mathrm{NaCl})$ or $(\mathrm{c}, \mathrm{d}) \mathrm{cLHRH}-\mathrm{I}\left(5 \mu \mathrm{g} \mathrm{kg}{ }^{-1} \mathrm{body}\right.$ weight $)$ at week 16 .

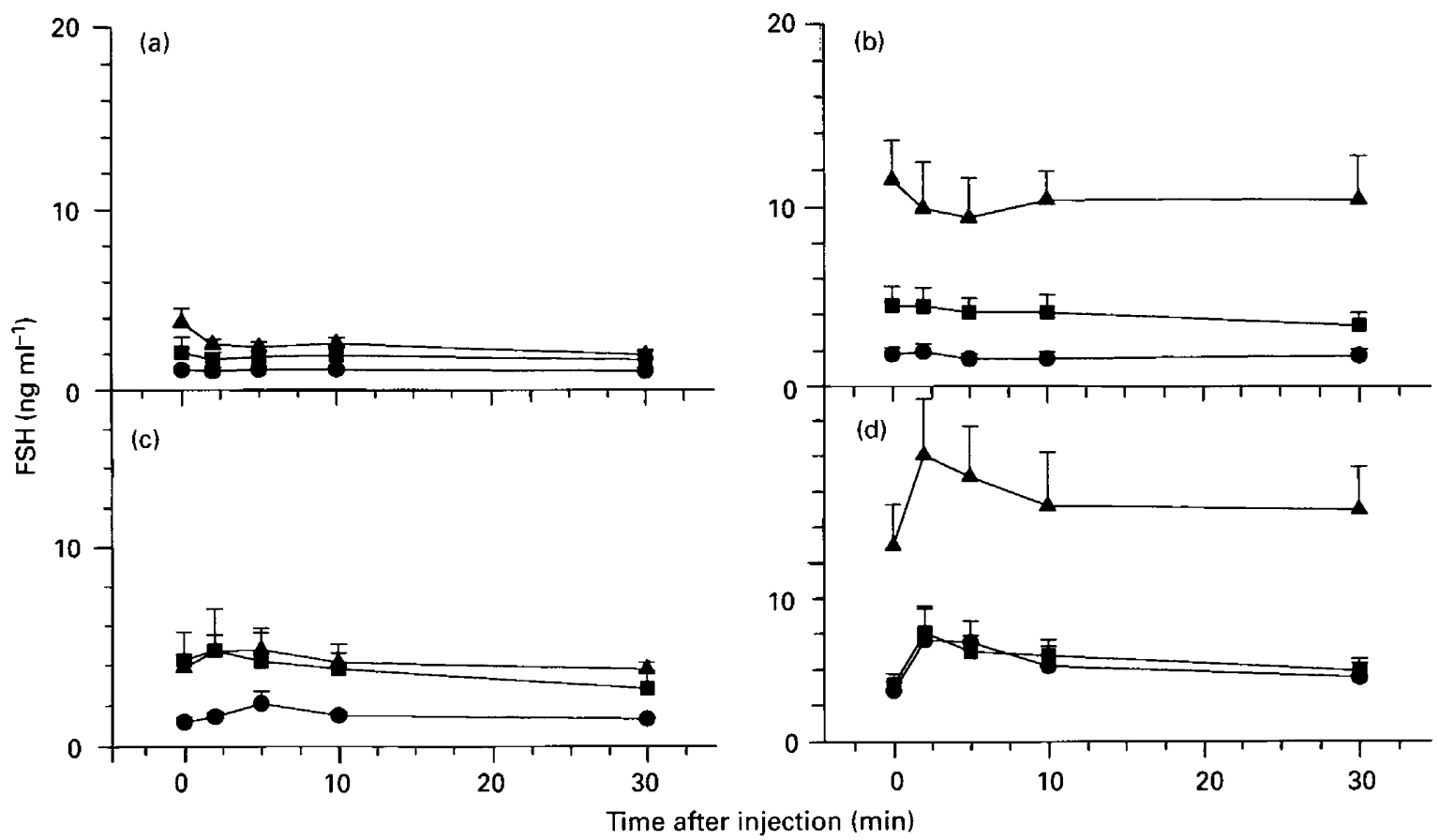

Fig. 3. Plasma FSH concentrations in $(a, c)$ intact and $(b, d)$ ovariectomized animals of restricted $(\bullet)$, intermediate $(\square)$ and $a d$ libitum (A) fed broiler breeder females after treatment with $(\mathrm{a}, \mathrm{b})$ saline $(0.9 \% \mathrm{NaCl})$ or $(\mathrm{c}, \mathrm{d}) \mathrm{cLHRH}-\mathrm{I}\left(5 \mu \mathrm{g} \mathrm{kg}{ }^{-1}\right.$ body weight $)$ at week 16. 

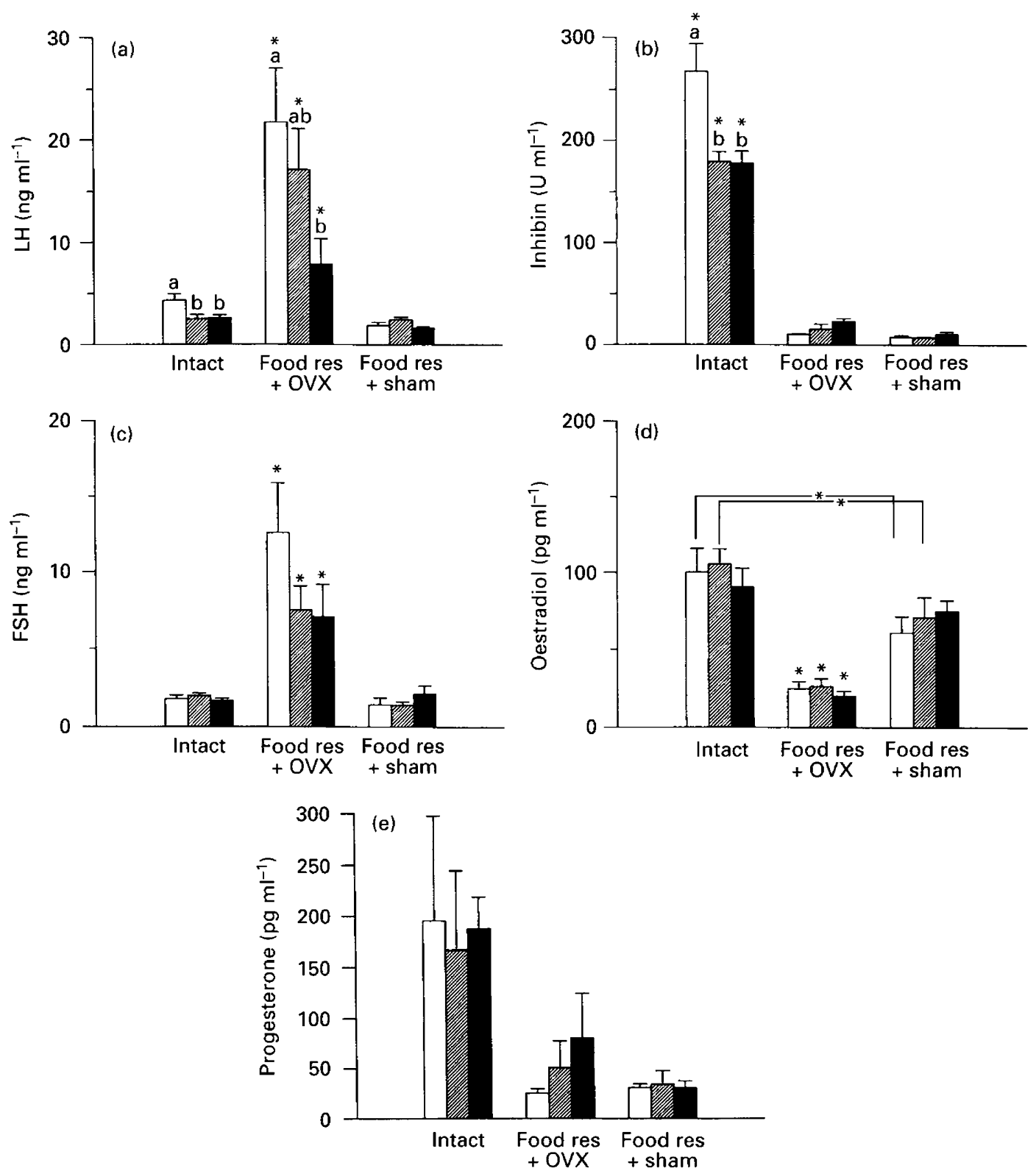

Fig. 4. Concentrations of (a) LH, (b) inhibin, (c) FSH, (d) oestradiol and (e) progesterone in intact, food restricted ovariectomized (OVX) and food restricted sham-operated (sham) animals of restricted $(\square)$, intermediate (שa) and ad libitum $(\square)$ fed broiler breeder females at week 39. Significant differences $(P<0.05)$ between feeding groups of the same gonad groups are indicated by different letters. Asterisks indicate significant differences between gonad groups of the same feeding group $(P<0.05)$.

those found in intact or sham-operated animals in all three food groups $(P<0.05)$. In ovariectomized birds, LH concentrations were higher in the Res group compared with the Ad lib animals $(P<0.05)$. Short-term food restriction followed by sham-operation tended to decrease $\mathrm{LH}$ concentrations in all groups.

Intact Res birds had the highest inhibin concentrations $\left(267.3 \pm 27.1 \mathrm{U} \mathrm{ml}^{-1}\right)$ compared with the Ad lib and Int groups $(P<0.005)$. Ovariectomy and sham-operation after short term food restriction caused sharp decreases of inhibin values in all groups $(P<0.0001)$. Differences among groups were not observed after both treatments.
Oestradiol concentrations showed a significant decrease in the Res and Int birds after short-term food restriction compared with those of intact birds $(P<0.005)$. Ovariectomy was followed by a further significant drop in oestradiol concentrations in all groups. In all treatments, no differences among food groups could be observed.

Owing to large variations in progesterone concentrations among individual intact birds, no significant differences were found between intact, ovariectomized or shamoperated birds. However, there was a clear tendency of decreasing progesterone concentrations in sham-operated or ovariectomized birds in comparison with intact hens. 

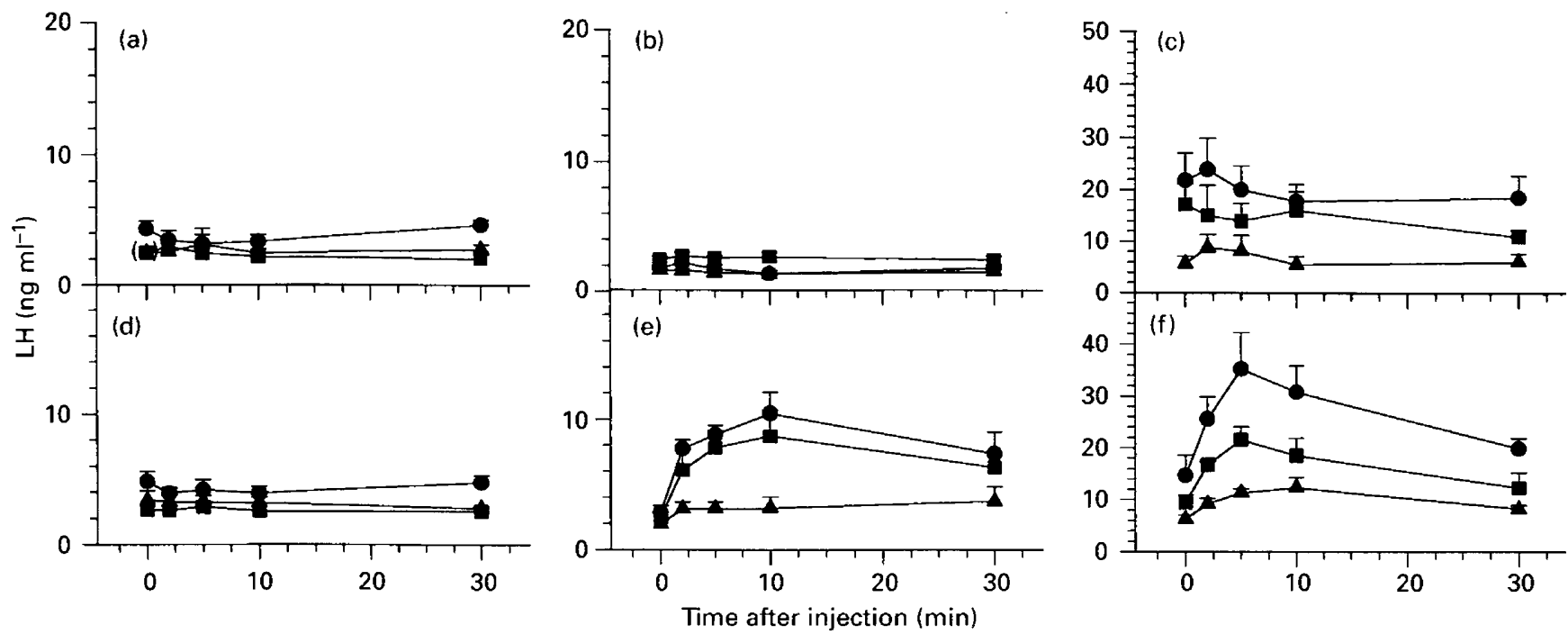

Fig. 5. Plasma LH concentrations in (a,d) intact, $(b, e)$ food restricted sham-operated, and (c,f) food restricted ovariectomized animals of restricted $(\mathbf{\bullet})$, intermediate $(\boldsymbol{\square})$ and ad libitum $(\mathbf{A})$ fed broiler breeder females after treatment with $(\mathrm{a}-\mathrm{c})$ saline $(0.9 \% \mathrm{NaCl})$ or $(\mathrm{d}-\mathrm{f}) \mathrm{cLHRH}-\mathrm{I}$ (5 $\mu \mathrm{g} \mathrm{kg}^{-1}$ body weight) at week 39 .

\section{Effect of cLHRH-I injections into intact, sham-operated and ovariectomized animals on LH and FSH concentrations at 39 weeks of age}

At the age of 39 weeks, all three feeding groups of intact birds failed to respond to saline or CLHRH-I injection (Fig. 5).

After short-term food restriction (sham-operated birds), $\mathrm{LH}$ values of the Res and Int birds showed significant increases in response to CLHRH-I injections and remained high for the duration of the experiment $(P<0.05)$ (Fig. 5). LH increased to a maximum concentration $10 \mathrm{~min}$ after injection to $761.9 \%$ for the Res group and $324.3 \%$ for the Int group of their respective control values (saline) $(P<0.005)$. The Ad lib group showed a weak response to $\mathrm{CLHRH}-\mathrm{I}$, although this was not significant compared with saline values. In all ovariectomized food groups, cLHRH-I injections increased LH concentrations above those of birds injected with saline in the first $10 \mathrm{~min}$, but tapered off rapidly to control concentrations thereafter. However, owing to differences in basal concentrations in saline and CLHRH-I treated animals, no significant effect of injection could be observed. Responses were significantly different among groups $(P<0.01)$ with the Res group showing the highest response and the Ad lib being the least responsive.

Basal FSH concentrations in the intact, sham-operated or ovariectomized birds did not change after saline or cLHRH-I injections in any of the feeding groups (Fig. 6).
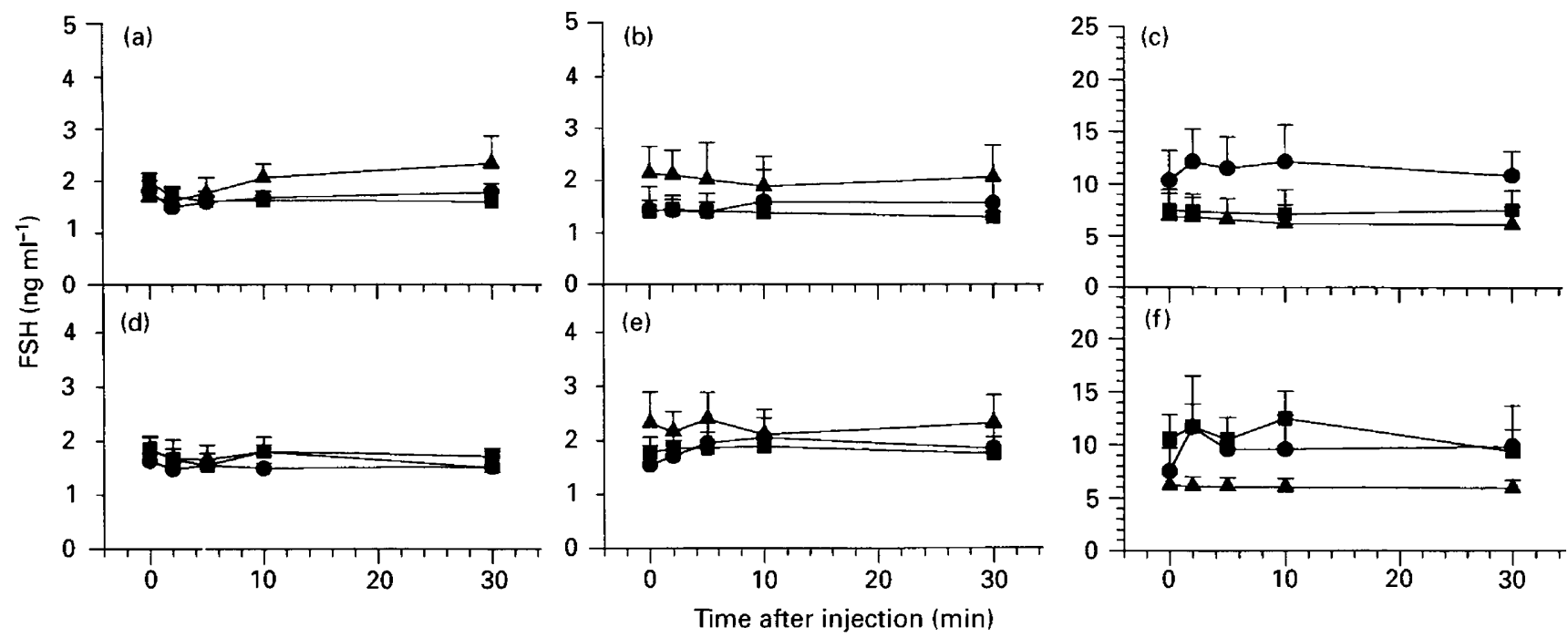

Fig. 6. Plasma FSH concentrations in $(a, d)$ intact, $(b, e)$ food restricted sham-operated, and $(c, f)$ food restricted ovariectomized animals of restricted $(\mathbf{O})$, intermediate $(\boldsymbol{\square})$ and ad libitum $(\mathbf{\Delta})$ fed broiler breeder females after treatment with $(\mathrm{a}-\mathrm{c})$ saline $(0.9 \% \mathrm{NaCl})$ or $(\mathrm{d}-\mathrm{f}) \mathrm{cLHRH}-\mathrm{I}$ ( $5 \mu \mathrm{g} \mathrm{kg}^{-1}$ body weight) at week 39 . 


\section{Discussion}

The present study shows that the amount of food intake can modify the sensitivity of the pituitary to cLHRH-I and possibly to ovarian factors before and after sexual maturity in broiler breeder females.

Before attainment of sexual maturity (week 16), basal LH concentrations were similar in the Ad lib, Int and Res birds for both intact and ovariectomized birds. This finding suggests that LH secretion is independent of possible feedback factors from the developing ovary. After cLHRH-I injections, the concentrations of LH increased rapidly in all feeding groups to similar concentrations, showing that the amount of feeding had no effect on the sensitivity of the pituitary for CLHRH-I. The rapid increase of LH in response to cLHRH-I injection is in agreement with the results of Wilson et al. (1989) in sexually immature chickens.

At week 16, the Ad lib group of intact animals showed higher FSH concentrations compared with the Int and Res groups, which coincides with the time of the prepubertal FSH peak that stimulates ovarian development. At this age, small yolky follicles were only present in the Ad lib birds and, to a lesser extent, in the Int group (Bruggeman, 1998). The earlier development of follicles at this age in the Ad lib group is further confirmed by the significant higher oestradiol concentrations, known to be produced mainly by the small yolky follicles (Nitta et al., 1991). In all groups of intact animals, inhibin concentrations were low, indicating that the large yellow follicles, which are the major source of inhibin production (Johnson et al., 1993; Chen and Johnson, 1996), are still absent at week 16. Intact birds of all feeding groups did not show any response of FSH to exogenously administered cLHRH-I. Ovariectomy induced a clear difference between the Ad lib group and the two other groups in basal FSH concentrations (Ad lib > Int $>$ Res). Besides the differential increases of basal FSH concentrations after ovariectomy, all ovariectomized groups tended to respond in the same way to cLHRH-I. These results all indicate that ad libitum feeding promotes basal FSH release, which culminates in rapid ovary development, follicular growth and higher oestradiol production, which in turn regulates FSH secretion. The magnitude of the effect of ovariectomy on oestradiol reduction and FSH increase in the Ad lib group compared with Res and Int groups confirms the earlier development of the reproductive axis in broiler breeder females fed ad libitum.

These results show that, in the period before sexual maturity, cLHRH-I controls LH and FSH release in different ways. In contrast to the clear effect of cLHRH-I on LH release, only a small effect on FSH secretion was observed either in the presence or absence of the ovary. As reported by Hattori et al. (1986) in immature male quails, it appears that FSH release is independent from cLHRH-I. Furthermore, the sensitivity of the pituitary to CLHRH-I in releasing LH and, to some extent, FSH is modified by ovarian substances. The lack of differences in $\mathrm{LH}$ in intact and ovariectomized birds, independently of amount of feeding, shows that its release does not depend on the ovarian feedback system at this age.

During the laying period (week 39), basal LH concentrations were higher in the intact Res birds compared with the Ad lib and Int groups. This finding confirms our earlier observations that the higher egg production in restricted broiler breeder females can be linked to higher plasma LH concentrations during laying (Bruggeman, 1998). There was no effect of cLHRH-I injection on LH concentrations in intact birds, probably due to the negative feedback of progesterone, produced by the large yolky follicles. This decreased sensitivity of the pituitary to exogenous CLHRH-I is confirmed by previous data (Bonney et al., 1974; Wilson and Sharp, 1975; Wilson et al., 1989). The slight decrease in LH and progesterone concentrations in the sham-operated (food restricted) chickens is consistent with results in laying hens (Johnson and Van Tienhoven, 1980; Tanabe et al., 1981; Decuypere et al., 1992; Vanmontfort et al., 1994). Ovariectomy resulted in sharp increases in $\mathrm{LH}$ concentrations in all groups, demonstrating that ovarian factors are involved in regulating $\mathrm{LH}$ release at this age. This finding is in agreement with the well-documented post-castration increase of gonadotrophins in chickens (Wilson and Sharp, 1976; Davies et al., 1980). The pronounced increase in basal LH concentrations in the ovariectomized Res birds, compared with the ovariectomized Int and Ad lib birds at week 39, indicates a differential sensitivity of the pituitary to the negative feedback effect of ovarian factors in the regulation of LH secretion. Moreover, the possibility of differences in basal endogenous LHRH secretion in ovariectomized animals due to different feeding levels cannot be excluded.

After sham-operation (food restriction) of the Res and Int birds, both groups responded to cLHRH-I by increasing LH secretion. The response was significantly lower in Ad lib birds. Ovariectomy caused a further differentiation among groups in cLHRH-I-stimulated LH secretion. The observed differences in responsiveness to cLHRH-I among differently fed ovariectomized and sham-operated animals cannot be explained by different concentrations in plasma steroid or inhibin concentrations. From these results, we hypothesize that a chronic food restriction of broiler breeder females, as recommended in practice, improves the sensitivity of the hypothalamic-pituitary axis (differences among ovariectomized animals) as well as its sensitivity to ovarian feedback factors (different sensitivity to cLHRH-I in shamoperated-ovariectomized versus intact animals) during the laying period. As a result, the LH-progesterone positive feedback mechanism, probably in combination with oestradiol-inhibin, which is important for inducing ovulation in birds (Wilson and Sharp, 1976), may differ among differentially fed animals. The mechanisms through which food intake modifies the sensitivity of the hypothalamic-pituitary axis needs further investigation.

Intact, sham-operated or ovariectomized animals showed no differences among groups in FSH concentrations at week 39. This finding is consistent with earlier data that, after establishment of lay, FSH concentrations tend to stabilize in intact animals (Bruggeman, 1998). The removal of the ovary caused a significant increase in FSH concentrations, indicating that the FSH release is controlled by ovarian factors. Although inhibin concentrations dropped sharply in all groups after short-term food restriction, FSH did not increase as expected since inhibin is considered to be the major negative feedback regulator of FSH at this age 
(Johnson et al., 1993; Vanmontfort et al., 1994, 1995). However, this lack of increase in FSH may be explained by the still relatively high concentrations of oestradiol produced by the remaining small follicles. Therefore, these findings suggest a differential endocrine role of inhibin and oestradiol in the feedback regulation of FSH secretion during the egg laying period. This hypothesis is further supported by the increases seen in FSH concentrations, due to the very low inhibin and oestradiol concentrations after ovariectomy of birds of all groups. In intact, sham-operated (food restricted) and ovariectomized animals, cLHRH-I injections did not cause any stimulation of FSH secretion in any of the groups. This finding suggests that, during the laying period, other factors such as inhibin and oestradiol are more important than cLHRH-I in the release of FSH.

In summary, the present study has demonstrated that the feeding regimen to which broiler breeder chickens are exposed can modify the sensitivity of the pituitary for cLHRH-I and, possibly, for gonadal hormones. Before sexual maturity, LH release (unlike FSH release) after cLHRH-I injection was independent of feeding levels and ovarian feedback factors. Animals fed ad libitum showed the highest responsiveness to ovarian factors (oestradiol rather than inhibin) and to cLHRH-I. However, after sexual maturation and establishment of lay, LH release by cLHRH-I was highly dependent on the amount of feeding and ovarian feedback regulation. Restricted feeding showed the highest responsiveness to both CLHRH-I and ovarian factors. However, at this age, the release of FSH was not influenced by exogenously administered cLHRH-I and was not affected by the amount of feeding.

The authors thank M. Hassansadeh Ladhmaki for his help with the surgery of the animals. They are grateful to R. Robertson and $D$. de Kretser for providing the inhibin radioimmunoassay kit, and to J. A. Proudman for providing the USDA FSH radioimmunoassay kit. V. Bruggeman was supported by grant number 942009 of the 'Vlaams Instituut voor de bevordering van het WetenschappelijkTechnologisch onderzoek in de industrie' (IWT). This research was supported by 'Het Onderzoeksfonds' (OT-project OT/95/19). L. Berghman and D. Vanmontfort were supported by the Fund for Scientific Investigation (FWO).

\section{References}

Bonney RC, Cunningham FJ and Furr BJA (1974) Effect of synthetic luteinizing hormone releasing hormone on plasma luteinizing hormone in the female domestic fowl Gallus domesticus. Journal of Endocrinology 63 539-547

Bruggeman V (1998) The Effect of Level and Timing of Food Restriction on Growth and Reproductive Characteristics and their Endocrine Control in Broiler Breeder Females PhD Thesis, Katholieke Universiteit Leuven

Bruggeman V, Vanmontfort D, Renaville R, Portetelle D and Decuypere E (1997) The effect of food intake from two weeks of age to sexual maturity on plasma growth hormone, insulin-like growth factor-I, insulin-like growth factor-binding proteins, and thyroid hormones in female broiler breeder chickens General and Comparative Endocrinology 107 212-220

Bruggeman V, D'Hondt E, Berghman L, Onagbesan O, Vanmontfort D, Vandesande $F$ and Decuypere $E$ (1998) The effect of food intake from 2 to 24 weeks of age on LHRH-I content in the median eminence and gonadotrophin levels in pituitary and plasma in female broiler breeder chickens General and Comparative Endocrinology 112 200-209

Cailleau J (1979) Radioimmunoassay of $17 \beta$-estradiol in human plasma Tijdschrift van de BVLT-Revue de l'ABTL 6 19-30
Chen C-C and Johnson PA (1996) Molecular cloning of inhibin/activin $\beta A$-subunit cDNA and expression of inhibin/activin $\alpha$ - and $\beta A$-subunits in the domestic hen Biology of Reproduction 55 450-454

Costa MJ (1981) Fundamental principles of broiler breeders nutrition and the design of feeding programs World Poultry Science 37 177-192

Davies DT, Massa R and James R (1980) Role of testosterone and of its metabolites in regulating gonadotrophin secretion in the Japanese quail Journal of Endocrinology 84 211-222

Decuypere E, Feng PY, Verheyen G and Vanmontfort D (1992) Induced stop of egg laying results in a transient LH-sensitivity of the progesterone producing cells both in vitro and in vivo. Ornis Scandinavia 23 340-345

Hattori A, Ishii S and Wada M (1986) Different mechanisms controlling FSH and LH release in Japanese quail (Coturnix coturnix japonica): evidence for an inherently spontaneous release and production of FSH Journal of Endocrinology 108 239-245

Hocking PM (1993) Effects of body weight at sexual maturity and the degree and age of restriction during rearing on the ovarian follicular hierarchy of broiler breeder females British Poultry Science 34 793-801

Hocking PM, Gilbert AB, Walker M and Waddington D (1987) Ovarian follicular structure of White Leghorns fed ad libitum and dwarf and normal birds fed ad libitum or restricted to point of lay British Poultry Science 28 493-506

Hocking PM, Waddington D, Walker MA and Gilbert AB (1989) Control of the development of the follicular hierarchy in broiler breeder pullets by food restriction during rearing British Poultry Science $30161-174$

Jaap RG and Muir FV (1968) Erratic oviposition and egg defects in broilertype pullets Poultry Science 47 417-423

Johnson AL and van Tienhoven A (1980) Hypothalamo-hypophyseal sensitivity to central injections of progesterone and LHRH in the laying and molting hen Advances in Physiological Science 33 99-107

Johnson PA, Brooks C, Wang S-Y and Chen C-C (1993) Plasma concentrations of immunoreactive inhibin and gonadotropins following removal of ovarian follicles in the domestic hen Biology of Reproduction 49 1026-1031

Krishnan KA, Proudman JA and Bahr JM (1992) Purification and characterization of chicken follicle-stimulating hormone Comparative Biochemistry and Physiology 102B 67-75

Krishnan KA, Proudman JA, Bolt DJ and Bahr JM (1993) Development of a homologous radioimmunoassay for chicken follicle-stimulating hormone and measurement of plasma FSH during the ovulatory cycle Comparative Biochemistry and Physiology 105A 729-734

Krishnan KA, Proudman JA and Bahr JM (1994) Purification and partial characterization of isoforms of luteinizing hormone from the chicken pituitary gland Comparative Biochemistry and Physiology 108B 253-264

McShane TM and Wise PM (1996) Life-long moderate caloric restriction prolongs reproductive life span in rats without interrupting estrous cyclicity: effects on the gonadotropin-releasing hormone/luteinizing hormone axis Biology of Reproduction 54 70-75

Nitta H, Osawa Y and Bahr JM (1991) Immunolocalization of steroidogenic cells in small follicles of the chicken ovary: anatomical arrangement and location of steroidogenic cells change during follicular development Domestic Animal Endocrinology 8 587-594

Proudman JA and Opel H (1981) Turkey prolactin: validation of a radioimmunoassay and measurement of changes associated with broodiness Biology of Reproduction 25 573-580

Roberson MS, Stumpf TT, Wolfe MW, Cupp AS, Kojima N, Werth LA, Kittok RJ and Kinder JE (1992) Circulating gonadotrophins during a period of restricted energy intake in relation to body condition in heifers Journal of Reproduction and Fertility $96461-469$

Robertson DM, Tsonis CG, McLachlan RI, Handelsman DJ, Leask R, Baird DT, McNeilly AS, Hayward S, Healy DL, Findlay JK, Burger HG and de Kretser DM (1988) Comparison of inhibin immunological and in vitro biological activities in human serum Journal of Clinical Endocrinology and Metabolism 67 438-443

Robertson DM, Giacometti M, Foulds LM, Lahnstein J, Goss NH, Hearn MTW and de Kretser DM (1989) Isolation of inhibin $\alpha$-subunit precursor proteins from bovine follicular fluid Endocrinology 125 2141-2149

Rombauts L, Vanmontfort D, Verhoeven G and Decuypere E (1992) Immunoreactive inhibin in plasma, amniotic fluid and gonadal tissue of male and female chick embryos Biology of Reproduction 46 1211-1216

SAS/STAT (1985) Guide for Personal Computers Version 6 Edition. Statistical Analysis System Institute Inc., Cary, NC

Schneyer AL, Mason AJ, Burton LE, Ziegner JR and Crowley WF, Jr (1990) Immunoreactive inhibin $\alpha$-subunit in human serum: implications for 
radioimmunoassay Journal of Clinical Endocrinology and Metabolism 70 $1208-1212$

Tanabe Y, Ogawa T and Nakamura T (1981) The effect of short-term starvation on pituitary and plasma $\mathrm{LH}$, plasma estradiol and progesterone, and on pituitary response to LHRH in the laying hen (Gallus domesticus) General and Comparative Endocrinology 43 392-398

Vanmontfort D, Berghman L, Rombauts L, Verhoeven $G$ and Decuypere $E$ (1994) Changes of immunoreactive inhibin, FSH, LH and progesterone in plasma after short-term food deprivation and during the ovulatory cycle of the domestic hen General and Comparative Endocrinology 95 117-124

Vanmontfort D, Berghman LR, Rombauts $L$, Verhoeven $G$ and Decuypere $E$ (1995) Developmental changes in immunoreactive inhibin and FSH in plasma of chickens from hatch to sexual maturity British Poultry Science 36 779-790

Verheyen G, Decuypere E, Chiasson RB, Vervloesem J, Kühn ER and Michels H (1987) Effect of exogenous LH on plasma concentration of progesterone and oestradiol in relation to the cessation of egg laying induced by different molting methods Journal of Reproduction and Fertility 81 13-21
Wakeling D (1985) New moulting programme keeps water on and adds limestone Poultry World 25 8-10

Wilson SC and Sharp PI (1975) Effects of progesterone and synthetic luteinizing hormone releasing hormone on the release of luteinizing hormone during sexual maturity in the hen (Gallus domesticus) Journal of Endocrinology 67 359-369

Wilson SC and Sharp PI (1976) Induction of luteinizing hormone release by gonadal steroids in the ovariectomized domestic hen Journal of Endocrinology 71 87-89

Wilson SC, Cunningham FJ, Chairil RA and Gladwell RT (1989) Maturational changes in the LH response of domestic fowl to synthetic chicken LHRH-I and -II Journal of Endocrinology 123 311-318

Yu MW, Robinson FE, Charles RG and Weingardt R (1992) Effect of feed allowance during rearing and breeding on female broiler breeders 2 . Ovarian morphology and production Poultry Science 71 1750-1761 